\title{
O BRINQUEDO TERAPÊUTICO NA ASSISTÊNCIA À CRIANÇA HOSPITALIZADA: SIGNIFICADO DA EXPERIÊNCIA PARA O ALUNO DE GRADUAÇÃO EM ENFERMAGEM*
}

\section{THE THERAPEUTIC PLAY USED FOR CARING A HOSPITALIZED CHILD: MEANING OF THE EXPERIENCE OF A NURSING UNDER GRADUATED STUDENT*}

Circéa Amalia Ribeiro**

RIBEIRO, C. A. O brinquedo terapêutico na assistência à criança hospitalizada: significado da experiência para o aluno de graduação em enfermagem. Rev.Esc.Enf.USP, v.32, n.1, p.73-9, abril. 1998.

\section{RESUMO:}

Este estudo consiste na análise fenomenológica do discurso de uma aluna do curso de graduação em Enfermagem, que utilizou o brinquedo terapêutico para assistir a uma criança hospitalizada. O objetivo do estudo é compreender o significado da experiência para esta estudante.

UNITERMOS: Brinquedo terapêutico, Criança hospitalizada, Enfermagem pediátrica, Análise fenomenológica.

\section{ABSTRACT:}

This study describes a phenomenological analysis of a nursing under graduated student's discourse, who used the therapeutic play for caring a hospitalized child. The goal of the study was to understand the meaning of the experience for this student.

UNITERMS: Therapeutic play, Hospitalized child, Paediatric nursing, Phenomenological analysis.

\section{INTRODUÇÃo}

Doença e hospitalização, geralmente acompanhadas de procedimentos intrusivos e dolorosos, constituem experiências altamente estressantes para a criança. Para assisti-la adequadamente é necessário que a enfermeira compreenda o que estas situações significam para a criança, reconheça o que a criança pode estar comunicando através do seu comportamento, o que em geral representa um pedido de ajuda, e utilize técnicas adequadas de comunicação e relacionamento.

Dentre os recursos disponíveis para a intervenção de enfermagem na assistência à criança, em nível emocional, encontra-se um valioso instrumento, o brinquedo, ou seja, a situação de brincar.
De acordo com FREUD (1975), brincar é a primeira atividade normal da mente que a criança apresenta e, segundo ABERASTURY (1992), a inibição constante para brincar, durante a infância, pode ser o único sintoma de neurose grave que uma criança apresenta.

Para MORAIS (1980), o brinquedo é de tal importância na vida da criança que se constitui em necessidade cuja satisfação tem precedência sobre outras consideradas básicas, a não ser que o organismo esteja em elevado estado de tensão, medo ou privação.

Brincar é primordial para a criança, esteja ela sadia ou doente, inclusive se, por uma circunstância de maior gravidade, precisar ser hospitalizada.

\footnotetext{
* Trabalho apresentado à Disciplina Problemática de Enfermagem do Programa de Doutorado Interunidades da Escola de Enfermagem da Universidade de São Paulo, ministrada pela Profa. Dra. Victória Secaf.

* Professor Adjunto do Departamento de Enfermagem da Universidade Federal de São Paulo, Disciplina Enferınagem Pediátrica. Doutoranda em Enfermagem.
} 
WHALLEY; WONG (1989) enfatizam que brincar é o trabalho da criança; é uma atividade essencial ao seu bem-estar mental, emocional e social e, da mesma forma que as demais necessidades de desenvolvimento, não pára quando a criança adoece ou é hospitalizada.

Assim, no hospital, o brinquedo deve ser utilizado para recrear, estimular, socializar e também para cumprir sua função terapêutica, ou catártica. Esta função constitui a base da ludoterapia ( técnica psiquiátrica infantil conduzida por médicos, enfermeiras psiquiatras ou psicólogos ) e também do brinquedo terapêutico ( técnica que segue os princípios da ludoterapia ). Este deve ser utilizado pela enfermeira que assiste a crianças hospitalizadas (GREEN, 1974).

Segundo STEELE (1981), o brinquedo terapêutico constitui-se num brinquedo estruturado para a criança aliviar a ansiedade gerada por experiências atípicas para sua idade, que costumam ser ameaçadoras e requerem mais do que recreação para resolver a ansiedade associada, devendo ser usado sempre que ela tiver dificuldade em compreender ou lidar com a experiência. De acordo com GREEN (1974), seu objetivo é dar ao observador a melhor compreensão das necessidades da criança. Para BARTON (1969) e CLATWORTH (1978), tem também a função de auxiliar no preparo da criança para procedimentos terapêuticos, assim como para que ela descarregue sua tensão após vivenciá-los.

Considerando o brinquedo terapêutico um importante instrumento de intervenção da enfermagem, na disciplina Enfermagem Pediátrica, os alunos de graduação são orientados sobre os benefícios de sua utilização para a criança. Durante essa orientação, são ressaltados os princípios teóricos que o norteam, a técnica de utilização e é oferecida bibliografia pertinente. $\mathrm{Na}$ atividade prática, os alunos são estimulados a utilizálo e auxiliados durante sua aplicação.

Trabalhos como os de MORAES et al.(1979), MARTINS; OHKI; FELLI (1979) e MARTINS; TRENCH; HECKMAIER (1979) descrevem a utilização do brinquedo terapêutico por estudantes de enfermagem em nosso meio. Entretanto, esses estudos referem-se muito mais ao significado da experiência para a criança do que para o estudante.

A criança, porém, não é o único sujeito envolvido na situação. $O$ adulto também tem uma participação importante durante o brinquedo terapêutico pois, conforme explica BARTON (1969), é essencial que a criança perceba a presença de um adulto aceitador que a encoraje a expressar seus sentimentos.

A vivência de utilizar o brinquedo terapêutico para assistir à criança hospitalizadla teve grande significado em minha vida profissional, como enfermeira e docente de Enfermagem Pediátrica, conforme relatado em estudo anterior RIBEIRO (1983).

É importante a compreensão desta experiência, para o aluno de graduação em Enfermagem, especialmente considerando o fato de que a utilização da técnica é pouco comum em nossas unidades pediátricas.

Nesta perspectiva, é de meu interesse descrever a vivência de uma aluna de graduação em Enfermagem, compreendendo sua singularidade a partir do significado atribuído a essa vivência.

Para tanto, o objetivo deste estudo é conhecer $e$ compreender o significado da experiência de utilizar o brinquedo terapêutico na assistência à criança hospitalizada, para o aluno de graduação em enfermagem.

\section{TRAJETÓRIA METODOLÓGICA}

Este estudo fundamenta-se na abordagem qualitativa que tem como princípios teóricos e metodológicos a fenomenologia

- Fenomenologia,segundoMARTINS(1992), é o estudo das essências. Esclarece ainda o autor que fenomenologia ê, neste século XX, o nome que se dá a um movimen to cujo objetivo é a investigação direta e a descrição de fenômenos que são experienciados pela consciência, sem teorias sobre a sua explicação causal e tão livre quanto possível de pressupostos e preconceitos.

A escolha dessa abordagem, para este estudo, deu-se pelo fato de a fenomenologia estar dirigida à busca dos significados que uma determinada experiência tem para os sujeitos que a vivenciam. Ela permite estudar o ser que se revela à consciência, numa atitude de acolhimento às percepções, pensamentos e sentimentos, procurando 0 pescuisador colocar-se na perspectiva do fenômeno estudado, para compreender como o outro a percebe, pensa e vive (MARTINS; BICUDO 1994).

De acordo com os autores ora mencionados, sendo uma modalidade de pesquisa qualitativa, não há preocupação com a generalização ou a comprovação dos fatos. Seu foco de atenção e interesse é centralizado no específico, no individual, procurando-se não a simples explicação, mas, sobretudo, a compreensão dos fenômenos estudados.

\section{O caminhar da pesquisa}

Este estudo constitui-se da análise fenomenológica do discurso de uma aluna de 
graduação em Enfermagem, de uma instituição de ensino federal da cidade de São Paulo, que utilizou o brinquedo terapêutico, para assistir a uma criança hospitalizada, durante o estágio de enfermagem pediátrica.

Obtive esse discurso através de uma entrevista gravada com a permissão da aluna e posteriormente o transcrevi na íntegra.

Como forma de desvelar o fenômeno, fiz à aluna a seguinte pergunta orientadora: "Como foi, para você, utilizar o brinquedo terapêtutico na assistência de enfermagem à criança hospitalizada?"

A seguir realizei análise do tipo fenomenologica, segundo a modalidade de estrutura do fenômeno situado. Segundo esta modalidade de análise, esclarecem MARTIS;BICUDO(1994), só há fenômeno enquanto houver um sujeito no qual ele se situa. Assim, o pesquisador está interessado no sujeito que está aprendendo, no sujeito que está com medo, no sujeito que está ansioso, ou seja, há sempre um sujeito, em uma situação, vivenciando um fenômeno. E esta vivência é também uma experiência,mas uma experiência percebida de modo consciente por aquele que a executa. Minha preocupação, neste estudo, é compreender como o sujeito, aluna de graduação em Enfermagem, vivenciou a experiência de utilizar o brinquedo terapêutico ao assistir uma criança hospitalizada.

As etapas de análise seguiram as orientações de MARTINS; BICUDO (1994) e são também descritas em pesquisa realizada por MERIGHI (1993), GARANHANI (1993)e ADEGAS (1996), conforme descreverei a seguir.

Inicialmente, com objetivo de apreender o sentido global do discurso, realizei várias leituras do mesmo e, depois, identifiquei e extraí dele as unidades de significado, transcrevendo-as na linguagem própria da entrevistada.

Como passo seguinte, fiz a redução fenomenológica das unidades de significado, reescrevendo-as de acordo com a minha visão, enquanto pesquisadora, para buscar a clareza de seu discurso.

Realizada a sintese dessas unidades, e reunindo-as com a finalidade de organizar as articulações do discurso, formei seis núcleos de pensamento, que serão aqui apresentados, interpretados e ilustrados com algumas falas extraídas do referido discurso.

\section{A dificuldade para prestar cuidados à criança}

A aluna mencionou que sentia dificuldade para prestar cuidados de enfermagem à criança, que não aceitava a realização dos procedimentos: reagia, chorava, ficava irritada e precisava ser contida.
“... eu estava cuidando de uma criança que não aceitava nenhum tipo de cuidado de enfermagem... ela chorava muito quando a gente ia fazer curativo... ela não deixava de jeito nenhum; precisava segurar e ficava muito irritada... ela também não aceitava a inalação... quando eu fui dar a primeira inalação, eu senti muita dificuldade: ela jogou tudo fora, não consegui fazer nada, nada, nada..."

\section{Aplicando o brinquedo terapêutico}

Ao utilizar o brinquedo terapêutico como um recurso para conseguir realizar os procedimentos, ofereceu à criança os mesmos materiais utilizados nos procedimentos, auxiliando-a a manuseá-los e sempre respeitando a sua disponibilidade para brincar. A criança dramatizou os procedimentos em um coelhinho. A aluna considerou que a falta de material disponível e a inexistência de espaço apropriado foram fatores que dificultaram a realização do brinquedo terapêutico.

“... como a gente tinha tido uma aula de brinquedo terapia, então eu resolvi aplicar para poder fazer a inalação. Então eu peguei todo o material de inalação, inclusive coloquei água dentro do potinho e liquei o oxigênio e coloquei no berço para ver como era a reação da criança ... e eu coloquei um coelhinho lá perto, ela pegou o coelhinho e começou a fazer inalação no coelhinho ..."

“... depois que terminou o curativo eu peguei e lavei as pinças $e$ ofereci para ela... ela pegou e comecou e não sabia ainda como mexer... ela foi pegando a gase $e$ colocando na barriga do coelhinho, no mesmo lugar aonde ela tinha, que eu fazia o curativo."

\section{O efeito do brinquedo terapêutico sobre o comportamento da criança}

Observou mudanças no comportamento da criança, que passou a aceitar a inalação, ficando até feliz e, embora continuasse a apresentar resistência à realização do curativo, fazia questão de dramatizá-lo e ela própria mostrava o seu cateter, quando solicitado. Constatou, após interrupção da assistência através do brinquedo, que houve regressão da aceitação do procedimento pela criança. 
"A partir dai ela comesou a fazer inalação todos os dias, ela ficava até feliz quando eu chegava com o potinh.o."

"... ela não deixava ninguém nem tocar .. se ia levantar a blusa dela, já chorava, não deixava. Então, a partir desse período de brinquedo terapia você chegava, perguntava para ela, ela mesma levantava a blusinha..."

"E aconteceu uma coisa engraçada da inalação, ..... apliquei na sexta -feira, que ela conseguiu sentar, fazer sozinha; dai veio sábado, domingo, e a gente teve dois dias seguidos de feriado. .... Entõo, quando eu voltei na quarta-feira, ela não estava aceitando mais e eu tive que recomeçar tudo de novo...."

40 brinquedo terapêutico e a valorização da assistência prestada

Percebeu que não só a enfermeira aprovou a assistência prestada com a utilização do brinquedo terapêutico, mas também os outros profissionais da unidade: auxiliar de enfermagem, médico, demais alunas de enfermagem, assim como a mãe da criança, reconheceram os efeitos dessa intervenção sobre o seu comportamento. A auxiliar de enfermagem, inclusive, lamentou o fato de não ter tempo de realizar este tipo de trabalho com as crianças

"A mãe achou muito bom ; ela também
notou diferenca na crianca. Os medicos
notaram, reconheceram. Teve alé uma
médica que foi concersar depois com a
professora e falou que tinha ajudado
muito esse trabalho que eu fiz com a
crianç..."

\section{Avaliando o resultado obtido como um incentivo}

Gostou muito da experiência, consiclerou-a válida. Aplicou o brinquedo, esperando uma mudança no comportamento da criança e avaliou que obter resultado positivo na primeira intervenção foi um incentivo para voltar a utilizá. lo. Reconheceu que a assistência emocional é sempre esquecida ou relegada ao último plano e acredita ser este o motivo pelo qual o brinquedo terapêutico é pouco utilizado, assim como a falta de tempo do pessoal.

“Eu gostei muito... a primeira vez que eu apliquei, logo em seguida veio o resultado... Você quer ver a criança menos traumatizada, chorar menos, ficar com menos medo."

“... A gente sempre esquece o psicológico, sempre, não tem jeito... essas coisas acabam ficando para último plano... por isso que eu acho que não é aplicado por aí; o pessoal sabe que é bom, já viu resultado e você não vê muita aplicação."

6 Prevendo dificuldades para a utilização do brinquedo terapêutico na vida profissional futura

Referiu que em sua vida profissional futura pretende utilizar o brinquedo terapêutico na assistência à criança, assim como favorecer sua utilização por toda a equipe. Prevê, entretanto, que terá dificuldades devido ao excesso de atividades desenvolvidas na assistência de enfermagem, afirmando que não tendo tempo suficiente, não deixará de fazer uma medicação ou um curativo para realizar uma sessão de brinquedo terapêutico.

“ Depende do lugar aonde eu for trabalhar... se for numa unidade muito grande e tiver pouco funcionário e tiver um monte de coisa para fazer, eu acho que é um pouco dificil fazer isso mesmo que a gente queira. Você vai deixar de fazer um curativo? De dar uma medicação?"

\section{REFLETINDO SOBRE O FENÔMENO DESVELADO}

O discurso da aluna revelou que ter utilizado o brinquedo terapêutico na assistência à criança foi, para ela, uma experiência gratificante, uma vez que constatou o efeito positivo dessa intervenção sobre o comportamento da criança, favorecendo a aceitação de procedimentos aos quais a paciente estava sendo submetida.

Tal mudança é descrita em vários trabalhos referentes à utilização do brinquedo terapêutico na assistência de enfermagem à criança hospitalizada, entre os quais pode-se destacar os de GREEN (1975), 
CLATWORTH (1978), RIBEIRO (1983, 1991), ANGELO (1985), PINHEIRO; LOPES (1993), ANGLIN; SAWYER (1993) e MARTINS (1995).

Explicações para este fato são dadas por importantes autores. FREUD (1975) enfatiza que a criança repete em seu brinquedo tudo o que lhe causou impressão, no sentido de tornar-se senhora da situação.

Para Piaget apud ERICKSON (1958) a repetição de uma situação difícil, durante o brinquedo da criança, não ocorre no sentido de preservar a dor decorrente da situação, mas sim para que ela possa ser dominada e se torne até produtora de prazer, através de uma assimilação total da atividade pelo ego da criança.

Segundo BET'TELHEIN (1988), o brinquedo permite à criança liberdade para transformar um acontecimento do qual foi sujeito passivo em outro em que ela é o provocador e o controlador ativo.

ALTMAN (1993) ressalta que ao brincar, a criança enferma, que em geral tem um retrocesso em seu desenvolvimento, é estimulada e retoma o impacto vital, recuperando-se mental e fisicamente; readquire a auto-confiança, consegue comunicar-se e cria coragem para ultrapassar a adversidade.

De acordo com ERIKSON (1971), expressarse através do brinquedo é a forma mais natural de autoterapia que a criança dispõe e, portanto, diz ele. "através do brinquedo podemos ajudar a criança a ajudar-se a si mesma".

Outro comentário que consiclero importante fazer é o fato de a criança ter voltado a recusar-se a realizar um procedimento após ter ocorrido uma interrupção das sessões de brinquedo terapêutico, nos dias em que a aluna esteve ausente da unidade pediátrica. Isto, a meu ver, demonstra uma desvinculação entre o que é ensinado e praticado pelos alunos e a assistência de enfermagem prestada de rotina à criança e reflete a necessidade de uma melhor integração docente assistencial, para que o ensino e a assistência de enfermagem sejam favorecidos.

Segundo o discurso, a aluna percebeu o reconhecimento de sua atuação pelos demais profissionais da equipe de saúde, assim como pela mãe da criança, fato bem evidenciado em uma de suas falas:

"Os médicos notaram, reconheceram. Teve até uma médica que foi conversar depois com a professora e falou que tinha ajudado muito esse trabalho que eu fiz com a criança".

Fato similar, narrado por MARTINS; OHKI; FELLI (1979), sugere que prestar este tipo de assistência pode inclusive favorecer o prestígio e o reconhecimento do enfermeiro pelos demais membros da equipe de saúde, assim como pelo cliente, no caso a criança e seus pais.

De acordo com PETRILLO; SANGER (1972), e importante que os vários profissionais de saúde brinquem com a criança para que, entre outras coisas, ela perceba que estes profissionais não estão sempre relacionados à dor. Além do mais, conforme considera D'ANTONIO (1984), o brinquedo terapêutico é benéfico tanto para a criança como para a enfermeira, pois conhecer o que está sendo manifestado pela criança e responder adequadamente a tais manifestaçãoes é prazeiroso e promove sentimentos positivos e relaxamento de tensão, também da enfermeira.

A experiência levou-a também a refletir sobre sua futura atuação profissional como enfermeira, referindo que procurará utilizar o brinquedo terapêutico na assistência à criança hospitalizada e facilitar sua utilização por toda a equipe. Prevê, entretanto, que o excesso de atividades que terá que desempenhar poderá dificultar ou impedir a utilização da técnica.

Permitiu, ainda, o reconhecimento de que apesar cle ser importante, a assistência emocional ao paciente é geralmente esquecida ou deixada para último plano; acredita ser este o motivo pelo qual o brinquedo terapêutico é pouco utilizado em nosso meio.

Estes comentários coincidem com as declaracões de MANZOLLI; CARVALHO; RODRIGUES (1981) as quais consideram que, embora o cuidado emocional do paciente seja responsabilidade de toda a equipe de saúde, quem pode mais ativamente desempenhá-lo é o enfermeiro por ser quem permanece mais tempo junto ao paciente; só que isto não vem acontecendo porque, por despreparo, os enfermeiros têm demonstrado grande deficiência de atuação nesta área.

Apesar do discurso holistico, a enfermagem continua prestando uma assistência fragmentada que privilegia of f́́sico, o biológico, em detrimento do emocional. Assim, segundo o discurso, parece que a estudante não apreendeu que o brinquedo terapêutico deve compor a realização de um procedimento tanto quanto a técnica em si.

Desta forma, a compreensão da necessidade da criança brincar, como necessidade básica, é essencial ao pessoal hospitalar para que o brinquedo seja valorizado tanto quanto a higiene, a alimentação, o curativo, a medicação, e não seja considerado apenas como uma atividade a mais, que a criança vai ter se der tempo ou se as pessoas que lhe prestam assistência estiverem a fim. Ou seja, as atividades de brinquedo devem ser parte integrante do cuidado de enfermagem. 
Por fim, o discurso revela que o conflito entre o pensar, o fazer e o sentir, presente no cotidiano do enfermeiro, descrito por PADREDI (1993), já começa a ocorrer durante o proprio curso de Enfermagem, pois temos a seguinte fala da aluna entrevistada:

"Sempre que tiver tempo, que der, se der" para aplicar aonde eu estiver trabalhando ... depende do lugar aonde eu for trabalhar ...Se for numa unidade muito grande, tiver pouco funcionário e um monte de coisa para fazer, eu acho que é um pouco dificil de fazer isso, mesmo que a gente queira. Não que não seja importante, é muito importante isso ..."

Através da descrição do comportamento da criança, feita pela aluna entrevistada, ficam demonstrados, mais uma vez, os benefícios da utilização do brinquedo terapêutico para assistir à criança hospitalizada.

Para mim, que tenho estudado esse tema, fica reiterada a necessidade de manter o compromisso de divulgá-lo e realizar trabalho integrado com os enfermeiros assistenciais, no sentido de contribuir para que o brinquedo terapêutico passe a ser efetivamente utilizado na assistência à criança.

Quanto ao ensino dessa forma de intervenção de enfermagem, acredito que deva ser reavaliado a fim de que o aluno perceba o brinquedo terapêutico não so como importante, mas sim como essencial e indispensável à assistência de enfermagem à criança hospitalizada

\section{REFERÊNCIAS BIBLIOGRÁFICAS}

ABERASTURY, A. A criança e seus jogos. 2ed. Porto Alegre, Artes Médicas, 1992.

ADEGAS,G.A.M. Consulta de enfermagem em puericultura: o significado para as mães. São Paulo, 1996. 94p. Tese (Mestrado) - Universidade Federal de Sao Paulo, Escola Paulista de Medicina.

ALTMAN, R.Z. [Orelha]. In: LINDQUIST,I. A criança no hospital: terapia pelo brinquedo. São Paulo, Página Aberta, 1993

ÂNGELO, M. Brinquedo: um caminho para a compreensão da criança hospitalizada. Rev.Esc.Enf.USP, v.19, n.3, p.213-23, 1985 .

ANGLIN, L.L.V.; SAWYER, E.H. Incorporating play interventions into nursing care. Pediatr. Nurs., v.19, n.5, p.459-63, 1993.

BARTON, P.H. Nursing assessment and intervention through play. In: BERGERSON, B.S. et al. Current concepts in clinical nursing. Saint Louis, Mosby, 1969. p.203-17.
BETTELHEIM, B. Uma vida para seu filho. Rio de Janeiro, Campus, 1988. cap.16, p.167-78: Brincadeira como solução de problemas.

CLATWORTH, S.M. The effect of therapeutic play on the anxiety behaviors of hospitalized children. Ann Arbv, Univerdity Microfilms Intermational, 1978. 226p. (Doctoral Degree). Boston University School of Education.

D'ANTONIO,I.J. Therapeutic use of play in hospitals. Nurs. Clin. Nortl. Am. v. 119, n.2, p.351-9, 1984.

ERICKSON, F. Reactions of children to hospital experience Nurs. Outlook, v.6, n.9, p.501-4, 1958.

ERIKSON, E.H. Infância e sociedade. Rio de Janeiro, Zahar 1971.

FREUD, S. Alćm do princípio do prazer. Rio de Janeiro, Imago, 1975 .

GARANHANI,M.L. O significado da cirurgia para a criança. Ribeirăo Preto, 1993, 155p. Dissertação (Mestrado). Escola de Enfermagem de Ribeirão Preto, Universidade de são Paulo

GREEN, C.S. Larry though puppet play "childish" but it helped him face his fears. Nursing, v.5, n.3, p.30-3, 1975

GREEN, C.S. Understanding children's needs trough therapeutic play. Nursing, v.4, n.10, p.31-2, 1974.

MANZOLLI, M.C.; CARVALHO, E.C.; RODRIGUES, A.F.R. Psicologia em enfermagem. Såo Paulo, Savier, 1981.

MARTINS, D.M.R.; OHII, A.E.; FELLI, V.E.A. Assistência de enfermagem a crianças hospitalizadas, quando enfrentam situaçōes desagradáveis (parte I). Rev.Esc.Enf USP L. $_{\perp}$, n.2, p.157-69. 1979 .

MARTINS, D.M.R.; TRENCH, M.H.; HECKMAIER, M. Assistência de enfermagem a crianças hospitalizadas, quando enfrentain situaçбes desagradáveis (parte II). Rev.Esc.Enf. USP, v.13, n.3. p.287-99, 1979

MARTINS, J. Um enfoque fenomenológico do currículo: educação como poésis. São Paulo, Cortez, 1992

MARTINS, J.; BICUDO, M.A.V. A pesquisa qualitativa em psicologia. 2.ed. São Paulo, EDVC, 1994.

MARTINS,M.R. Protocolo de preparação da criança préescolar para punção venosa, com utilização do brinquedo terapêutico._São Paulo, 1995. 56p. Monografia (Especializaçáo) - Departamento de Enfermagem da Universidade Federal de São Paulo.

MERIGH, M.A.B. A docência de enfermagem em uma universidade pública - um enfoque fenomenológico. São Paulo, 1993. 217p. Tese (Doutorado). Escola de Enfermagem, Universidade de Sao Paulo.

MORAES, E. et al. Estudantes de enfermagem assistem crianças doentes utilizando "entrevista com brincadeira" Rev.Esc.Enf. USP, v.13, n.1, p.29-39, 1979. 
MORAIS, M.L.S. O faz-de-conta e a realidade social da criança. Săo Paulo, 1980. 363p. Dissertaçăo (Mestrado) . Instituto de Psicologia, Universidade de São Paulo.

PADREDI, F.S.M. O bom-senso ao invés da teoria e o improviso ao invés da administração - uma análise do fazer, do pensar e do sentir no cotidiano do enfermeiro. Săo Paulo. 1993. 94p. Dissertaça (Mestrado) Escola de Enfermagem, Universidade de São Paulo.

PETRILLO, M.; SANGER, S. Cuidado emocional del niño hospitalizado. México, La Prensa Médica Mexicana, 1972 cap.5, p.111-49: El juego en el hospital.

PINHEIRO, M.C.D.; LOPES G.T. A influência do brinquedo na humanização da assisténcia de enfermagem à criança hospitalizada. Rev.Bras.Enf., v.46, n.2, p.117-31, 1993.
PIAGET, J. In: ERICKSON, F. Reactions of children to hospital experience. Nurs Outlook, v.9, n.6, p.501-4, 1958.

RIBEIRO, C.A. O efeito da utilização do brinquedo terapêutico, pela enfermeira pediatra, sobre o comportamento de crianças recém-hospitalizadas. Rev.Esc.Enf.USP, v.25, n.1, p.41-60, 1991.

RIBEIRO, C.A. Sentindo o valor das experiências significativas para a aprendizagem: relato de duas situaçoes vividas com crianças hospitalizadas. Rev.Esc.Enf.USP, v. 17, n.3, p.159203,1983 .

STEELE, S. Child health and the family. New York, Masson, 1981. cap.11, p.705-38: Concept of communication.

WHALEY, E.H.; WONG, D.L. Enfermagem pediátrica. Rio de Janeiro, Guanabara, 1989. 